\title{
Annual Daylight Quality of Typical Classrooms in Sun-Deficient Areas
}

\author{
Yang Guan ${ }^{1}$, Yonghong Yan ${ }^{2 *}$, Siqi $\mathrm{He}^{2}$, Bohan Zhang ${ }^{3}$ \\ ${ }^{1}$ Department of Art and Technology, Sichuan Fine Art Institute, Chongqing 401331, China \\ ${ }^{2}$ Faculty of Architecture and Urban Planning, Chongqing University, Chongqing 400044, China \\ ${ }^{3}$ Faculty of Art \& Science, New College, University of Toronto, Toronto M5S 2E8, Canada
}

Corresponding Author Email: yanyonghong@cqu.edu.cn

https://doi.org/10.18280/ijsdp.150509

Received: 5 February 2020

Accepted: 18 May 2020

\section{Keywords:}

daylight, dynamic analysis, classroom, temporal map, spatial variation

\begin{abstract}
This paper aims to disclose the daylight features in sun-deficient areas of China. For this purpose, the authors carried out field measurement with annual dynamic analysis on daylight in a university of Chongqing, a typical sun-deficient area. The annual daylight quality was evaluated in details from the angles of temporal and spatial variations. Specifically, the annual daylight data were condensed into 72 similar time periods according to the local academic calendar. The mean illuminance and spatial ratio of areas meeting the illuminance threshold were calculated in each period for two typical classrooms in the university. The results show that, in the south-facing classroom, the mean daylight illuminance on the desktop was below the threshold in winter and in early mornings (before 10:00) and late afternoons (after 16:00) of other seasons; in the north-facing classroom, the mean daylight illuminance on the desktop were below the threshold in virtually all 72 periods. In terms of space, less than $25 \%$ of the north-facing classroom and 55\% in the south-facing classroom met the illuminance threshold. Compared with the traditional daylight evaluation methods, our strategy realizes a comprehensive and detailed evaluation of indoor daylight quality, shedding new light on reasonable lighting improvement.
\end{abstract}

\section{INTRODUCTION}

The inexhaustible natural resource of daylight should be properly used to save power consumption, protect human health, and improve work quality [1-3]. Sun-deficient areas in China, such as Chongqing and Sichuan, only possess half of the natural light resources of sun-sufficient areas [4]. In such areas, indoor artificial light is frequently used during the day. If the artificial light is too strong, a huge amount of energy will be wasted; if the artificial light is too weak, the health of the occupants will be threatened. To rationalize the intensity of artificial light, it is highly necessary to analyze the dynamic distribution of indoor daylight.

At present, the daylight is mainly evaluated statically with metrics like daylight factor $[5,6]$. However, the daylight is a time-varying resource, under the combined effects of solar movement, season, and weather, all of which are constantly changing. There are some time-based metrics of the daylight, namely, daylight autonomy (DA) [7, 8], useful daylight illuminance (UDI) [9], annual light exposure (ALE) and annual sunlight exposure (ASE) [10]. These metrics compress the annual data on daylight into an acceptable ratio or a cumulative amount. But none of them could take account of the times or areas where the daylight is below the recording threshold.

To solve the problem, Kleindienst et al. [11] proposed a new daylight evaluation strategy that compresses the huge annual dataset into a workable size of typical values, and displays the annual dataset on an institutive surface map, which greatly facilitating daylight evaluation. Inspired by Kleindienst's strategy, this paper dynamically analyzes the classroom daylight quality in Chongqing, a sun-deficient area in China, according to the local school hours. Chongqing was selected as the study area, because it belongs to Class V light climate region (the area with the poorest daylight resources). Through the analysis, clear, intuitive images and detailed numerical reports were generated to provide the timing and duration of the daylight, as well as the parts of classroom requiring supplementary artificial light. The research results help to protect the health of students and save power consumption.

\section{FIELD MEASUREMENT}

Our analysis targets ten classrooms on three campuses of Chongqing University. These classrooms differ in size, orientation, purpose, and construction time. According to Method of Daylighting Measurements (GBT5699-2017) [12], a field measurement was carried out from 10:00 to 14:00 on an overcast day to ascertain the building features and lighting condition of each classroom. The facades and plans of the classrooms are displayed in Table 1. It can be seen that the ten classrooms belong to three different scales: the large scale of $120-150 \mathrm{~m}^{2}$, the medium scale of $80-100 \mathrm{~m}^{2}$, and the small scale of $30-50 \mathrm{~m}^{2}$.

According to the Standard for Daylighting Design of Buildings (GB 50033-2013) [5], the daylight factor of classrooms in Chongqing should reach $3.6 \%$, and the average daylight illuminance should be up to 4501x. The daylight measurement results (Figure 1) show that six of the ten 
classrooms satisfy the threshold of daylight factor, but most classroom did not meet the thresholds of uniformity and illuminance. The field measurement only obtains traditional daylighting parameters. Further analysis is needed to identify the annual daylighting features.

Table 1. Façades and plans of the ten classrooms

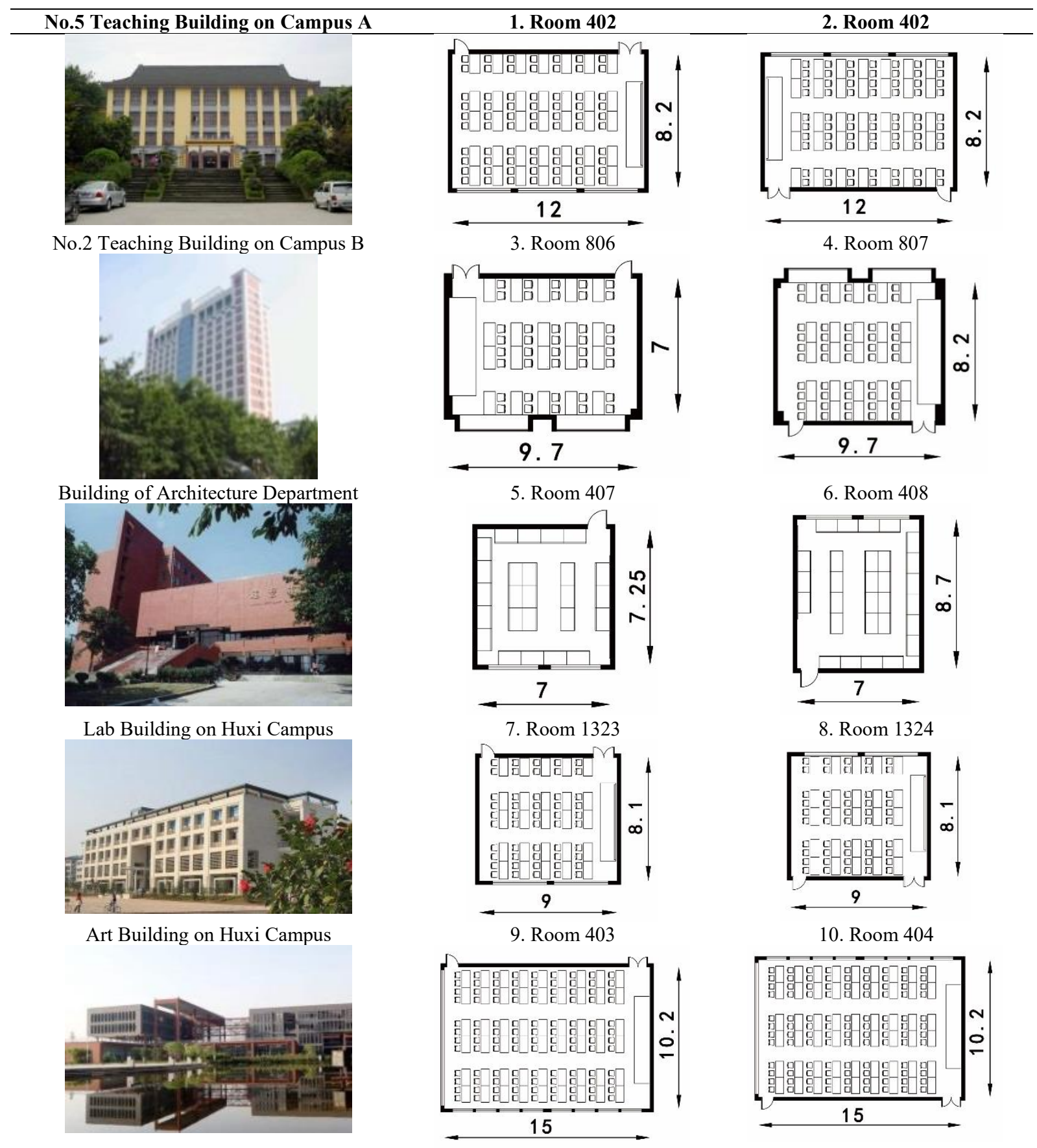



(a) Daylight factor



(b) Average illuminance 


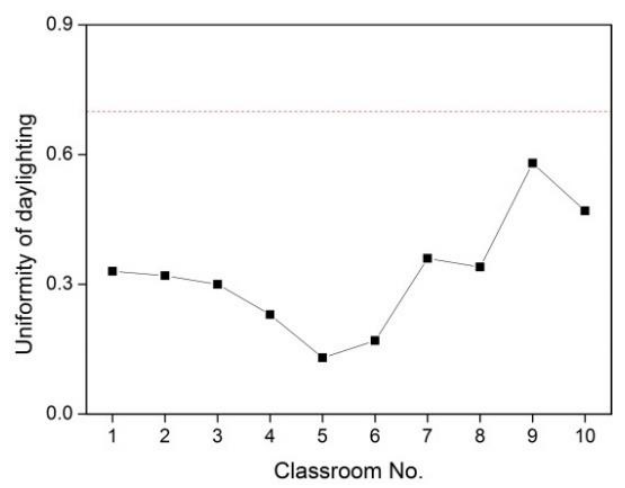

(c) Uniformity

Figure 1. Daylighting parameters of the ten classrooms

\section{METHODOLOGY}

The classrooms in Chongqing generally fall into three scales: large $\left(120-150 \mathrm{~m}^{2}\right)$, medium $\left(80-100 \mathrm{~m}^{2}\right)$, and small $\left(30-50 \mathrm{~m}^{2}\right)$. The most common type of classrooms belongs to the medium scale and face south or north. By these standards, there are two typical classrooms among the ten targets, namely, Room 806 and Room 807 of No.2 Teaching Building on Campus B. The two classrooms are of the same size and interior materials. The reflectance of the interior surfaces in the two classrooms was measured by a Konica Minolta CL-500A spectroradiometer. The results (Table 2) show that the window has a transmittance of $78.2 \%$.

Table 2. Reflectance of interior surfaces

\begin{tabular}{cc}
\hline Surface & Reflectance (\%) \\
\hline Wall & 78.3 \\
Ceiling & 59.5 \\
Floor & 36.7 \\
Wood door & 28.5 \\
Blackboard & 12.76 \\
Desktop & 13.8 \\
\hline
\end{tabular}

\subsection{Relevant temporal analysis methods}

Mardaljevic [13] designed the temporal map to improve the sensitivity of daylight factor to factors like building orientation and weather. With hours of the day and days of the year as axes, the temporal map displays the annual daylight data on a surface map, revealing the temporal variation of daylight quality in a dense format. Based on temporal map, Sian Kleindiens et al. [11] simplified the annual dataset by splitting the year into a few small periods called similar moments, and computed the daylight value in each period with the ASRCCIE sky model [14]. This paper combines the above two approaches to acquire the details on the daylight quality in the selected classrooms, and demonstrate the spatial and temporal variations of the daylight.

\subsubsection{Temporal map}

The annual daylight quality was calculated by DAYSIM in $5 \mathrm{~min}$ intervals, and used to draw the temporal map on MATLAB. The large daylight dataset was mapped to a surface map, with vertical axis being the hours of the day and horizontal axis being the days of the year. Within the time grid, the variation in daylight quality is intuitively illustrated by color deference.

\subsubsection{Numerical analysis}

Numerical analysis is another essential element of daylight evaluation. For example, 4001x and 500lx in the temporal map are too similar in color to be distinguished by human eyes. In terms of numerical values, one of them is above the illuminance threshold (4501x) for artificial light, while the other is below that threshold.

Therefore, numerical analysis was also adopted in our research. Drawing on Sian Kleindienst's strategy, the year was divided into 56 similar periods ( 7 intervals for a day, and 8 intervals for a year), and the illuminance of each period was calculated at the central sun position.

In each similar period, the calculation result may be affected by the weather and sky brightness. According to the form of sky brightness and the frequencies of each sky type, hourly typical meteorological year (TMY2) data [15] were averaged over each period by Perez's ASRC-CIE sky model, which has been validated for diverse climates and sky zones. The governing equation of the ASRC-CIE model can be expressed as:

$$
E_{v c}=b_{c} E_{v c . c i e . c}+b_{c t} E_{v c . c i e . c t}+b_{i} E_{v c . c i e . i}+b_{o} E_{v c . c i e . o}
$$

where, $E_{\mathrm{vc}}$ is the illuminance at a sensor point; $E_{v c . c i e . c}, E_{v c . c i e . c t}$, $E_{v c . c i e . i,}$, and $E_{\text {v.cie.o }}$ are the illuminances at the sensor point under standard CIE clear sky, standard CIE clear turbid sky, standard CIE intermediate sky and standard CIE overcast sky, respectively; $b_{c}, b_{c t}, b_{i}$ and $b_{o}$ are the frequencies of the four sky types, respectively. These frequencies depend on sky clearness $\varepsilon$ and brightness $\boldsymbol{\Delta}$ [14], which can be calculated using the horizontal diffuse irradiance, the normal incident irradiance, and the solar zenith angle.

\subsubsection{Temporal analysis method}

As discussed above, Kleindienst divided a year into 56 periods of similar moments. But this division method does not suit the academic calendar in Chongqing. For one thing, Kleindienst's division cannot distinguish the holidays of the local school year from the remainder of the year: Kleindienst divided a day into seven intervals and a year into eight, such that each period in the year spans across 1.5 months, while schools in Chongqing do not open in February, July, and August. For another, the daily division (from sunrise to sunset) by Kleindienst is not in sync with the typical daily schedule of local schools: the school hours last from 8:00 to 18:00, including $45 \mathrm{~min}$-long lessons and $10 \mathrm{~min}$-long breaks between every two lessons. 
Therefore, this paper proposes a new division method: each day (8:00-18:00, excluding the lunch break in 12:00-14:00) was split into eight $1 \mathrm{~h}$-long periods; each year (excluding February, July, and August) was divided into 9 periods by month. In total, 72 periods ( 8 hours of the day, and 9 months of the year) were designed for temporal analysis. This division method helps to display the daylight features in each lesson, excluding holidays, and identify the lessons with the worst daylight quality.

To sum up, our daylight evaluation includes two parts: an intuitive graphic analysis, and an accurate numerical analysis. The graphic analysis mainly draws a temporal map that represents the annual light variations in condensed form. The numerical analysis, extended from the Kleindienst's approach, divides each year into 72 periods, and computes the typical daylight value in each period. The 72 typical daylight values plus the temporal map provide a more comprehensive and detailed evaluation of classroom daylight quality than traditional indices like daylight factor.

In addition, dynamic analysis is an inevitable trend of daylight evaluation. The most popular dynamic analysis method is the DA, which compresses the annual data into a concise value, reflecting the ratio of work hours above the illuminance benchmark. Similarly, this paper relies on suitable details to condense the annual data into 72 typical illuminance values. Rooted in local academic calendar, our method reflects the daylighting features in each lesson in different months.

\subsection{Validation of our method}

Before computation, our method was verified through RADIANCE simulation under clear sky conditions to examine whether the mean bias error (MBE) between the actual and simulated illuminances falls in the acceptable range. The horizontal illuminance with $0.5 \mathrm{~m}$ grid at $0.8 \mathrm{~m}$ above the floor (on the desktop) was measured from $8: 30$ to $17: 30$ in $1 \mathrm{~h}$ intervals. Figure 2 shows the mean illuminance on the desktop measured in the classrooms and computed by RADIANCE. The simulation parameters are as follows: -ab 3 -aa 0.15 -ar
128 -ad 512 -as 128. As shown in Figure 2, the small MBEs (within $\pm 10 \%$ ) confirm that the simulated illuminance agreed with the measured data, indicating that the parameters in our research are reliable.

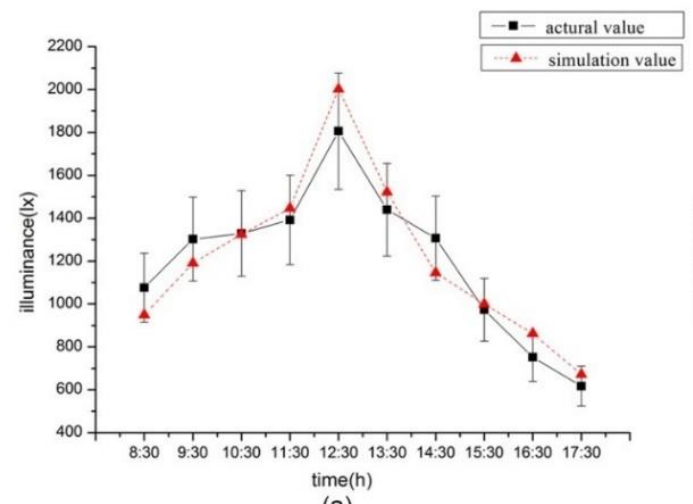

(a)

(a) South-facing classroom

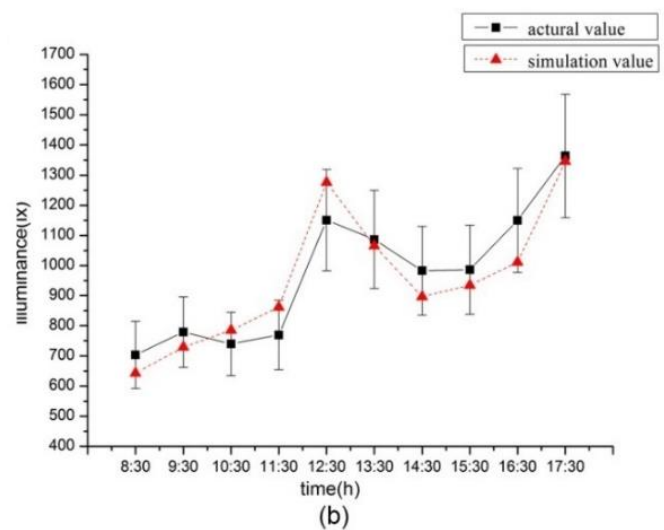

(b) North-facing classroom

Figure 2. The MBEs between actual and simulated illuminances

\subsection{Analysis of temporal variation}

Table 3. Mean daylight illuminance (lx) of typical classrooms in 72 periods: (a) south-facing classroom

\begin{tabular}{ccccccccc}
\hline & $\mathbf{8 : 0 0 - 9 : 0 0}$ & $\mathbf{9 : 0 0 - 1 0 : 0 0}$ & $\mathbf{1 0 : 0 0 - 1 1 : 0 0}$ & $\mathbf{1 1 : 0 0 - 1 2 : 0 0}$ & $\mathbf{1 4 : 0 0 - 1 5 : 0 0}$ & $\mathbf{1 5 : 0 0 - 1 6 : 0 0}$ & $\mathbf{1 6 : 0 0 - 1 7 : 0 0}$ & $\mathbf{1 7 : 0 0 - 1 8 : 0 0}$ \\
\hline Jan & 96.57 & 228.86 & 349.53 & 500.41 & 749.98 & 537.62 & 262.08 & 87.15 \\
Mar & 210.86 & 431.27 & 768.70 & 1078.70 & 809.42 & 649.97 & 396.46 & 203.99 \\
Apr & 352.47 & 619.67 & 862.96 & 691.54 & 624.20 & 523.26 & 409.36 & 250.17 \\
May & 341.25 & 489.08 & 612.11 & 602.71 & 565.06 & 581.06 & 480.87 & 304.64 \\
Jun & 343.42 & 472.32 & 522.53 & 646.83 & 559.24 & 510.09 & 435.79 & 301.66 \\
Sep & 323.58 & 723.29 & 1000.58 & $1274.26^{*}$ & 727.70 & 629.31 & 377.74 & 206.91 \\
Oct & 217.29 & 390.73 & 778.98 & 1104.98 & 703.07 & 455.15 & 249.47 & 103.32 \\
Nov & 177.15 & 340.21 & 489.87 & 830.99 & 489.24 & 330.80 & 194.70 & 48.76 \\
Dec & 109.24 & 214.22 & 321.36 & 390.97 & 613.21 & 442.55 & 201.22 & $42.65^{*}$ \\
\hline
\end{tabular}

(b) north-facing classroom

\begin{tabular}{ccccccccc}
\hline & $\mathbf{8 : 0 0 - 9 : 0 0}$ & $\mathbf{9 : 0 0 - 1 0 : 0 0}$ & $\mathbf{1 0 : 0 0 - 1 1 : 0 0}$ & $\mathbf{1 1 : 0 0 - 1 2 : 0 0}$ & $\mathbf{1 4 : 0 0 - 1 5 : 0 0}$ & $\mathbf{1 5 : 0 0 - 1 6 : 0 0}$ & $\mathbf{1 6 : 0 0 - 1 7 : 0 0}$ & $\mathbf{1 7 : 0 0 - 1 8 : 0 0}$ \\
\hline Jan & 75.09 & 163.73 & 235.97 & 283.92 & 286.94 & 241.31 & 164.08 & 68.05 \\
Mar & 163.86 & 263.14 & 332.76 & 363.20 & 384.02 & 362.92 & 278.46 & 159.68 \\
Apr & 242.01 & 339.42 & 382.69 & 404.25 & 412.59 & 392.80 & 328.81 & 209.01 \\
May & 265.54 & 359.05 & 389.58 & 378.58 & 423.39 & $499.22 *$ & 468.30 & 315.87 \\
Jun & 269.89 & 361.53 & 402.20 & 355.06 & 444.14 & 428.64 & 402.93 & 268.49 \\
Sep & 217.03 & 314.72 & 350.60 & 367.81 & 394.64 & 384.99 & 290.82 & 167.63 \\
Oct & 170.03 & 258.95 & 321.65 & 342.95 & 338.36 & 283.24 & 187.67 & 81.69 \\
Nov & 126.39 & 210.71 & 272.28 & 309.13 & 283.27 & 221.53 & 137.87 & 38.03 \\
Dec & 86.34 & 169.33 & 236.26 & 279.82 & 262.25 & 211.94 & 129.47 & $33.50^{*}$ \\
\hline
\end{tabular}



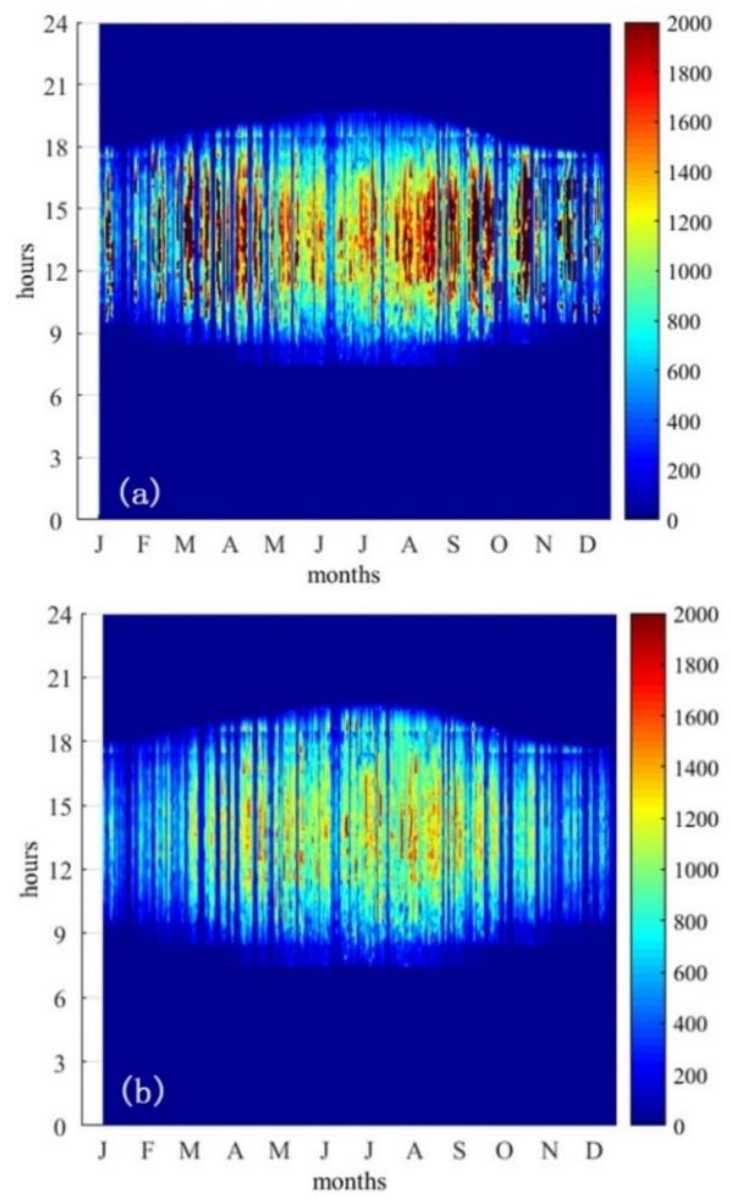

Figure 3. Temporal maps of mean illuminance in southfacing (a) and north-facing (b) classrooms

As mentioned above, a year was divided into 72 periods. For each period, daylight illuminances with $0.5 \mathrm{~m}$ grid at $0.8 \mathrm{~m}$ above the floor in the typical north-facing and south-facing classrooms were calculated. The results are listed in Table 3, with the highest and lowest values marked with asterisks and the values below the illuminance threshold (450lx) marked in bold.
In addition, temporal maps (Figure 3) were drawn in MATLAB based on annual horizontal illuminance calculated by DAYSIM in $5 \mathrm{~min}$ intervals.

\subsection{Analysis of spatial variation}
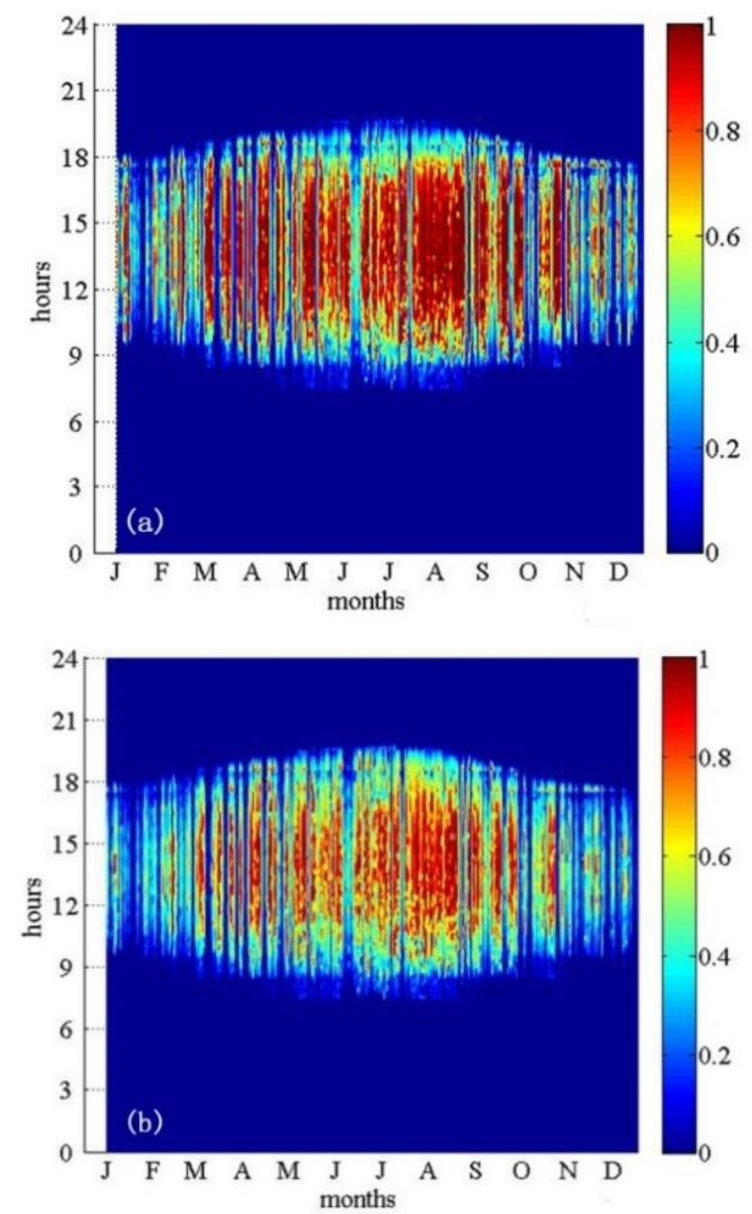

Figure 4. Temporal maps of spatial ratios in the south-facing (a) and north-facing (b) classrooms

Table 4. Spatial proportion of area fulfilling daylight standard threshold: (a) south-facing classroom

\begin{tabular}{|c|c|c|c|c|c|c|c|c|}
\hline & 8:00-9:00 & 9:00-10:00 & 10:00-11:00 & $11: 00-12: 00$ & $14: 00-15: 00$ & $15: 00-16: 00$ & $16: 00-17: 00$ & 17:00-18:00 \\
\hline Jan & $1.05 \%$ & $14.04 \%$ & $25.26 \%$ & $29.12 \%$ & $35.09 \%$ & $28.07 \%$ & $18.60 \%$ & $0.70 \%$ \\
\hline Mar & $12.98 \%$ & $27.37 \%$ & $41.40 \%$ & $47.37 \%$ & $47.02 \%$ & $38.60 \%$ & $25.61 \%$ & $12.98 \%$ \\
\hline Apr & $22.81 \%$ & $38.60 \%$ & $44.21 \%$ & $43.86 \%$ & $38.60 \%$ & $35.09 \%$ & $27.72 \%$ & $15.09 \%$ \\
\hline May & $21.75 \%$ & $34.04 \%$ & $41.40 \%$ & $41.05 \%$ & $36.49 \%$ & $39.30 \%$ & $32.28 \%$ & $19.65 \%$ \\
\hline Jun & $21.05 \%$ & $31.58 \%$ & $41.05 \%$ & $35.79 \%$ & $36.84 \%$ & $34.74 \%$ & $28.77 \%$ & $19.65 \%$ \\
\hline Sep & $21.75 \%$ & $40.35 \%$ & $48.07 \%$ & $51.58 \% *$ & $41.75 \%$ & $36.84 \%$ & $25.61 \%$ & $12.98 \%$ \\
\hline Oct & $13.33 \%$ & $25.61 \%$ & $41.75 \%$ & $49.47 \%$ & $38.60 \%$ & $28.42 \%$ & $15.09 \%$ & $2.46 \%$ \\
\hline Nov & $10.53 \%$ & $26.32 \%$ & $29.12 \%$ & $41.05 \%$ & $28.42 \%$ & $21.05 \%$ & $13.33 \%$ & $0.00 \% *$ \\
\hline Dec & $2.81 \%$ & $13.33 \%$ & $21.40 \%$ & $26.67 \%$ & $30.88 \%$ & $25.26 \%$ & $14.39 \%$ & $0.00 \% *$ \\
\hline
\end{tabular}

(b) north-facing classroom

\begin{tabular}{|c|c|c|c|c|c|c|c|c|}
\hline & 8:00-9:00 & 9:00-10:00 & 10:00-11:00 & 11:00-12:00 & 14:00-15:00 & 15:00-16:00 & $16: 00-17: 00$ & 17:00-18:00 \\
\hline Jan & $0.00 \% *$ & $2.17 \%$ & $6.81 \%$ & $8.67 \%$ & $8.67 \%$ & $6.81 \%$ & $2.17 \%$ & $0.00 \% *$ \\
\hline Mar & $2.17 \%$ & $8.36 \%$ & $14.24 \%$ & $15.48 \%$ & $15.79 \%$ & $15.79 \%$ & $8.67 \%$ & $1.86 \%$ \\
\hline Apr & $6.81 \%$ & $14.55 \%$ & $16.10 \%$ & $18.27 \%$ & $18.58 \%$ & $16.41 \%$ & $13.62 \%$ & $3.72 \%$ \\
\hline May & $8.67 \%$ & $15.48 \%$ & $16.41 \%$ & $15.79 \%$ & $19.20 \%$ & $23.84 \% *$ & $21.67 \%$ & $9.60 \%$ \\
\hline Jun & $8.67 \%$ & $15.17 \%$ & $17.65 \%$ & $14.86 \%$ & $20.74 \%$ & $19.81 \%$ & $16.41 \%$ & $8.98 \%$ \\
\hline Sep & $4.33 \%$ & $12.38 \%$ & $15.17 \%$ & $15.79 \%$ & $17.03 \%$ & $16.41 \%$ & $9.29 \%$ & $2.17 \%$ \\
\hline Oct & $2.48 \%$ & $8.05 \%$ & $12.69 \%$ & $14.24 \%$ & $13.93 \%$ & $8.67 \%$ & $3.10 \%$ & $0.00 \% *$ \\
\hline Nov & $0.00 \% *$ & $4.02 \%$ & $8.67 \%$ & $10.84 \%$ & $8.67 \%$ & $5.26 \%$ & $0.00 \% *$ & $0.00 \% *$ \\
\hline Dec & $0.00 \% *$ & $2.48 \%$ & $6.81 \%$ & $8.67 \%$ & $8.36 \%$ & $3.72 \%$ & $0.00 \% *$ & $0.00 \% *$ \\
\hline
\end{tabular}


According to the Standard for Daylighting Design of Buildings (GB 50033-2013) [5], the horizontal illuminance of daylight on the desktop in each classroom should not fall below 4501x. Hence, the spatial ratio of areas meeting that threshold was counted based on the illuminance data of a $0.5 \mathrm{~m}$ grid at $0.8 \mathrm{~m}$ above the ground in each typical classroom. Calculations were performed in each of the 72 periods and the results are listed in Table 4. Temporal maps (Figure 4) of the spatial ratios were also drawn.

To identify the spatial distribution of daylight, two extreme conditions, the clear sky on summer solstice and the overcast sky on winter solstice, were selected for spatial rendering from morning to twilight (Figure 5). The contour of 4501x was drawn to highlight the areas failing to meet the illuminance threshold.

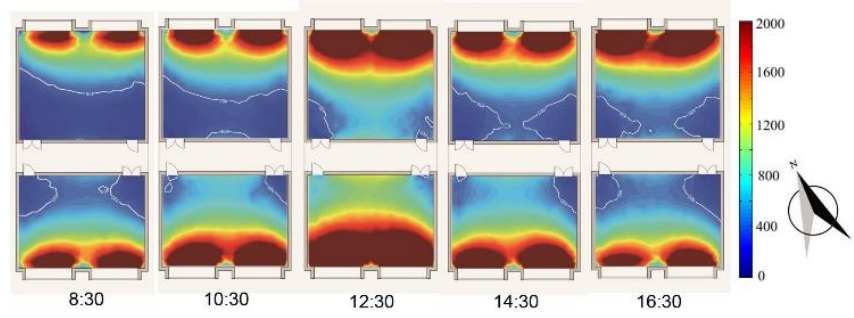

(a)

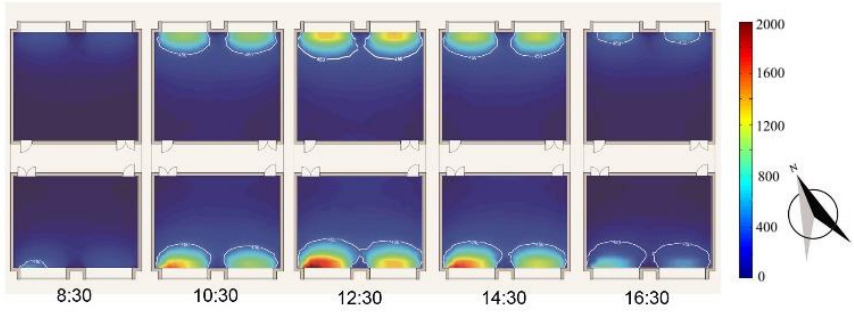

(b)

Figure 5. Renderings of spatial illuminance on (a) summer solstice and (b) winter solstice

\section{RESULTS ANALYSIS}

\subsection{Temporal variation}

As shown in Figure 3, the temporal map of the south-facing classroom, with many high illuminance spots in spring and fall, was redder than the map of the north-facing classroom, indicating that the overall illuminance of the south-facing classroom is higher than that of the north-facing classroom.

As shown in Table 3, in the south-facing classroom, the worst daylight quality occurred in January and December. The mean illuminances were virtually all below 4501x, except 11:00-16:00 in January and 14:00-15:00 in December. The daylight quality was slightly better in March, October, and November, when the mean illuminances exceeded 4501x from 10:00 to 16:00. Longer daily duration meets the standard requirement (9:00-16:00) in April, June, and September. The daylight quality in May was the best, as the mean illuminance met the standard from 9:00 to 17:00. In the north-facing classroom, the mean illuminances on the desktop were below the threshold in almost all 72 periods.

\subsection{Spatial variation}

As shown in Figure 4, the spatial ratio map of the south- facing classroom was darker than that of the north-facing classroom, that is, the former classroom has more areas that meet the illuminance threshold.

As shown in Table 4, the spatial ratio of areas meeting the illuminance threshold was not satisfactory. The ratio was below $25 \%$ in the north-facing classroom, and below 55\% in the south-facing classroom. This means artificial light is needed at least for the 3/4 away from the windows in the northfacing classroom, and for the $1 / 2$ in the south-facing classroom.

As shown in Figure 5, not all the spaces in classrooms met the illuminance threshold, even under the strongest solar radiation. The illuminances at the front and back of the classrooms, which are far away from the windows were below 4501x. On winter solstice, the classrooms had extremely poor lighting conditions due to the lowest level of daylight. The worst daylight quality was observed at 8:00 when the illuminances of both classrooms were entirely below the threshold. At 12:30, only about $1 / 3$ of the total area in each classroom met the daylighting requirement.

\section{CONCLUSIONS}

In this paper, the daylight in ten classrooms of Chongqing, a sun-deficient area of China, were measured. The measurement shows that, although $60 \%$ of these classrooms satisfied the daylight factor required by Chinese national standard, the mean illuminance and uniformity of most classroom were below the specified thresholds.

Then, two out of the ten classrooms were selected for further analysis on annual daylight features. The annual daylight data were divided into 72 periods, and the mean illuminance and spatial ratio of areas meeting the illuminance threshold in each classroom were calculated in each of the 72 periods. In terms of time, the desktop illuminance was often below the threshold in autumn and winter, as well as in the early morning and late afternoon of other seasons. In terms of space, the areas close to and far from the windows differed greatly in daylight distribution. Less than $25 \%$ of the north-facing classroom and $55 \%$ in the south-facing classroom met the illuminance threshold.

To make up for the lack of daylight, the best solution is to install an automatic dimming system. But this system is not yet widely used in China, due to economic and technological limitations [16-18]. Our dynamic analysis method is applicable to most schools in sun-deficient areas of China, for it can identify the periods with poor daylight quality. Artificial light must be provided in these periods. Moreover, spatial variation analysis sheds light on the spatial arrangement of artificial light. In addition, our method fully considers the local academic calendar, providing a good reference for similar research in other light climate regions.

However, the current daylight standard in China only specifies the lower limit of illuminance (4501x) supplied by daylight, failing to provide the upper limit. That is why this paper only compares the illuminance of each period against the threshold of 4501x, and advises on the timing and spatial area of artificial light. The future research will improve the scope and application of our method by including indices (e.g. glare probability and solar heat gain) other than illuminance, and samples from other sun-deficient areas or other climate regions. 


\section{ACKNOWLEDGMENT}

This research is supported by the National Natural Science Foundation of China (Grant No.: 51978097, 51778081), the Science and Technology Research Program of Chongqing Municipal Education Commission (Grant No.: KJQN201801003).

\section{REFERENCES}

[1] Chen, X., Yang, H. (2015). Combined thermal and daylight analysis of a typical public rental housing development to fulfil green building guidance in Hong Kong. Energy and Buildings, 108: 420-432. https://doi.org/10.1016/j.enbuild.2015.09.032

[2] García Fernández, B., Vázquez Moliní, D., Álvarez Fernández-Balbuena, A. (2017). Mathematical model applied to improve the natural lighting design. International Journal of Sustainable Development and Planning, 12(2): 273-282. http://dx.doi.org/10.2495/SDP-V12-N2-273-282

[3] Chen, X., Zhang, X., Du, J. (2019). Glazing type (colour and transmittance), daylighting, and human performances at a workspace: A full-scale experiment in Beijing. Building and Environment, 153: 168-185. https://doi.org/10.1016/j.buildenv.2019.02.034

[4] He, Y., Lin, Y. (2010). Analysis of China's daylighting climate with PGD diagram. Journal of Civil, Architectural \& Environmental Engineering, 2010(1): 111-114.

[5] GB 50033-2013. Standard for daylighting design of buildings. China Architecture \& Building Press. 2012.

[6] Chen, X.Q., Yao, J.F. (2011). Investigation and Analysis of the Luminous Environment of Some Middle and Primary School Classrooms in Chongqing. China Illuminating Engineering Journal, 22(2): 25-30. https://doi.org/10.13223/j.cnki.ciej.2011.02.006

[7] Reinhart, C.F., Walkenhorst, O. (2001). Validation of dynamic RADIANCE-based daylight simulations for a test office with external blinds. Energy and Buildings, 33(7): 683-697. https://doi.org/10.1016/S03787788(01)00058-5

[8] Acosta, I., Campano, M.Á., Domínguez, S., Fernández-
Agüera, J. (2019). Minimum daylight autonomy: A new concept to link daylight dynamic metrics with daylight factors. LEUKOS, 15(4): 251-269. https://doi.org/10.1080/15502724.2018.1564673

[9] Bian, Y. (2019). Daylighting for Buildings. China Achitecture \& Building Press: Beijing, China. ISBN 9787112237296.

[10] Nabil, A., Mardaljevic, J. (2006). Useful daylight illuminances: A replacement for daylight factors. Energy and Buildings, 38(7): 905-913. https://doi.org/10.1016/j.enbuild.2006.03.013

[11] Kleindienst, S., Bodart, M., Andersen, M. (2008). Graphical representation of climate-based daylight performance to support architectural design. Leukos, 5(1): $39-61$. https://doi.org/10.1080/15502724.2008.10747628

[12] GB/T5699-2008. Method of daylighting measurements. Standards Press of China. 2008.

[13] Mardaljevic, J. (2004). Spatio-temporal dynamics of solar shading for a parametrically defined roof system. Energy and Buildings, 36(8): 815-823. https://doi.org/10.1016/j.enbuild.2004.01.020

[14] Perez, R., Ineichen, P., Seals, R., Michalsky, J., Stewart, R. (1990). Modeling daylight availability and irradiance components from direct and global irradiance. Solar Energy, 44(5): 271-289. https://doi.org/10.1016/0038092X(90)90055-H

[15] Zhang, Q., Yang, H. (2012). Typical Meteorological Database Handbook for Buildings. China Building Industry Press, Beijing. ISBN 9787112137701.

[16] Yang, J., Zhai, X.M., Li, J., Wu, L.R., Guo, X.P. (2016). Classroom lighting situation in the primary and secondary school in the one county of Beijing. China Illuminating Engineering Journal, 27(12): 15-20.

[17] Gu, F., Zhang, R.H., Zou, Y., Meng, J. (2018). Sanitation monitoring of classroom daylight and illume in Zhejiang Province during 2015-2017. Chinese Journal of School Health, 39(6): $\quad 888-889, \quad 893$. https://doi.org/10.16835/j.cnki.1000-9817.2018.06.025

[18] Zhong, X., Hou, H.C., Qiao, Q.F. (2016). Application of LED intelligent lighting in the classroom of the primary and secondary school. China Illuminating Engineering Journal, 27(3): 54-60. 